\title{
Genetic diversity of the ATAQ gene in Rhipicephalus microplus collected in Mexico and implications as anti-tick vaccine
}

\author{
Sarah Melissa Lugo-Caro del Castillo ${ }^{1}$. Rubén Hernández-Ortiz ${ }^{2}$. Ninnet Gómez-Romero ${ }^{3}$. \\ Moisés Martínez-Velázquez ${ }^{4} \cdot$ Edgar Castro-Saines $^{2} \cdot$ Rodolfo Lagunes-Quintanilla $^{2}$ (b)
}

Received: 13 February 2020 / Accepted: 14 June 2020 / Published online: 22 June 2020

(C) Springer-Verlag GmbH Germany, part of Springer Nature 2020

\begin{abstract}
The cattle tick Rhipicephalus microplus has a large impact on cattle production due to its bloodsucking habit and transmission of pathogens that cause babesiosis and anaplasmosis. Application of acaricides constitutes the major control method but is often accompanied by serious drawbacks, including environmental contamination and an increase in acaricide resistance by ticks. The recent development of anti-tick vaccines has provided positive results in the post-genomic era, owing to the rise of reverse vaccinological and bioinformatics approaches to analyze and identify candidate protective antigens for use against ticks. The ATAQ protein is considered a novel antigen for the control of the cattle tick R. microplus; it is expressed in midguts and Malpighian tubules of all ticks from the Rhipicephalus genus. However, genetic diversity studies are required. Here, the $A T A Q$ gene was sequenced of seven $R$. microplus tick isolates from different regions in Mexico to understand the genetic diversity. The results showed that sequence identity among the Mexican isolates ranged between 98 and $100 \%$ and $97.8-$ $100 \%$ at the nucleotide and protein levels, respectively. Alignments of deduced amino acid sequences from different R. microplus ATAQ isolates in Mexico revealed a high degree of conservation. However, the Mexican isolates differed from the $R$. microplus "Mozambique" strain, at 20 amino acid residues. Finally, the analysis of more $R$. microplus isolates, and possibly of other Rhipicephalus species, to determine the genetic diversity in the ATAQ locus is essential to suggest this antigen as a vaccine candidate that might control tick infestations.
\end{abstract}

Keywords Rhipicephalus microplus · ATAQ · Genetic diversity · Tick vaccine

Section Editor: Neil Bruce Chilton

Rodolfo Lagunes-Quintanilla

rodolfo.lagunes@gmail.com

$1 \quad$ Universidad Politécnica del Estado de Morelos, Boulevard Cuauhnáhuac 566, Col. Lomas del Texcal, CP 62550 Jiutepec, Morelos, México

2 Centro Nacional de Investigación Disciplinaria en Salud Animal e Inocuidad - INIFAP, Carretera Federal Cuernavaca - Cuautla 8534, Col. Progreso, CP 62574 Jiutepec, Morelos, México

3 Laboratorio de Vacunología y Constatación, Facultad de Medicina Veterinaria y Zootecnia - UNAM, Avenida Universidad 3000, CP 04510 Ciudad de México, México

4 Centro de Investigación y Asistencia en Tecnología y Diseño del Estado de Jalisco A.C., Av. Normalistas 800, Col. Colinas de la Normal, CP 44270 Guadalajara, Jalisco, México

\section{Introduction}

The cattle tick Rhipicephalus microplus, is considered to be the most important ectoparasite in the tropics and subtropics worldwide (Almazán et al. 2010; Popara et al. 2013; Lagunes et al. 2016). Mexico has approximately 34 million head of cattle and it is estimated that about $80 \%$ of the cattle production is at risk of ticks and tick-borne diseases (TTBDs). Additionally, economic losses caused by R. microplus and TTBDs have been estimated to be US\$ 573.61 million per year (Rodríguez-Vivas et al. 2017). Recent efforts to control tick infestations using chemical acaricides have several limitations, including the increased acaricide resistance by ticks, environmental pollution, and contamination of food products with drug residues (Kaewmongkol et al. 2015; Ramírez et al. 2016). Vaccine development is a promising alternative to control tick infestations and pathogen transmission. Currently, 
two recombinant Bm86 protein-based vaccines are commercially available in Australia, Cuba, Mexico, and South America (Guerrero et al. 2012; Parizi et al. 2012; Schetters et al. 2016; Blecha et al. 2018). Nevertheless, variable efficacy levels against $R$. microplus strains in separate geographical locations are reported, which may be associated with natural allelic variations in the Bm86 protein and also physiological differences between tick species (Sossai et al. 2005; Blecha et al. 2018). Recently, the ATAQ protein was identified as a putative Bm86 homolog with high similarity; it is expressed in midgut and Malpighian tubules of all ticks from the Rhipicephalus genus, which suggests ATAQ as a candidate protein for vaccine development and a potential antigen for the control of the cattle tick $R$. microplus (Nijhof et al. 2010; Aguirre et al. 2016). However, genetic variability has been reported to be one of the reasons for reduced antigenicity in vaccines, making it necessary to obtain information from strains on different geographical regions to develop effective vaccines against infestations by $R$. microplus (Popara et al. 2013; Rodríguez-Mallon 2016). Thus, this study aimed to analyze the $A T A Q$ gene in $R$. microplus collected from several geographic locations in Mexico and compare the data with tick species previously reported in order to determine if the sequence variation in the $A T A Q$ locus could potentially affect the effectiveness of a possible anti-tick vaccine.

\section{Materials and methods}

\section{Ticks}

The R. microplus (Susceptible "Media Joya," "Huastecas," and "Hybrid") adult female ticks were obtained from laboratory colonies maintained at the CENID-SAI, INIFAP, Mexico. Originally, these tick strains were collected from infested cattle in Tapalpa, Jalisco, and Aldama, Tamaulipas, Mexico. Additionally, semi-engorged $R$. microplus ticks were collected from naturally infested cattle in Candelaria, Campeche; Santiago Ixcuintla (The Ranch: "Verdineño"), Nayarit; Aldama ("Vargas"), Tamaulipas; and Moyahua, Zacatecas, Mexico. Oviposition and hatching by female ticks in humidity chambers at 12-h light: 12-h dark photoperiod, $27^{\circ} \mathrm{C}$ and $95 \%$ relative humidity occurred at the CENID-SAI, INIFAP. Larvae were used for RNA extraction at 15 days after hatching, resulting in $7 R$. microplus tick isolates from different geographic locations of Mexico.

\section{RNA extraction and CDNA synthesis}

Approximately 100-150 unfed tick larvae from each $R$. microplus tick isolate were used for the experiment. Total RNA was extracted from homogenized tick samples using TRIzol reagent (Invitrogen, Carlsbad, CA) according to manufacturer's instructions. Synthesis of cDNA was carried out from $5 \mu \mathrm{g}$ of total RNA using RevertAid First Strand cDNA Synthesis (Thermo Scientific $\AA$ ). The cDNA was subsequently used as the template to amplify full length ATAQ gene (1818 bp) reported for the $R$. microplus "Mozambique" strain (GenBank Accession number GU144589.1).

\section{Amplification and cloning of $A T A Q$ gene}

Primers were designed to amplify and clone the full-length $A T A Q$ gene as follows: forward primer 5'-ATGG GAAGAATGAACAAC-3' and reverse primer 5'-TCAG GCCTCTTCCTCCGTTG-3'. The PCR was carried out with Platinum Taq DNA polymerase (Invitrogen) at $95{ }^{\circ} \mathrm{C}$ for $2 \mathrm{~min}$, followed by 35 cycles of $94{ }^{\circ} \mathrm{C}$ for $30 \mathrm{~s}, 60^{\circ} \mathrm{C}$ for $1 \mathrm{~min}$ and $72{ }^{\circ} \mathrm{C}$ for $1 \mathrm{~min}$, and a final extension step at $72{ }^{\circ} \mathrm{C}$ for $10 \mathrm{~min}$. PCR products were electrophoresed on $1 \%$ agarose gels to check the size of amplified fragments by comparison with a DNA molecular weight marker (1 kb Plus DNA Ladder, Invitrogen). Amplified fragments were purified (Wizard, Promega) and cloned using pCR®4-TOPO TA Cloning® Kit (Invitrogen). The plasmid constructs were used to transform E. coli strain TOP $10 \AA$ (Invitrogen), and the resultant clones were screened with PCR prior to growth in selective broth and plasmid isolation for DNA sequencing. At least five different clones from each PCR product were sequenced to rule out any sequencing errors.

\section{Sequence analysis}

Nucleotide sequences were generated in duplicate and both directions using a 3500xL Genetic Analyzer (Applied Biosystems/Hitachi, Forest City, CA). T7 (forward) and T3 (reverse) sequencing primers and the designed internal primers, 5'-ATCCTTACTACAAGTGCAACTGC-3' and 5'TGGCACTTTGGATCAGCTTCTC-3', were used to obtain full-length coverage of the $A T A Q$ gene. Nucleotide consensus sequences were obtained from each isolate and then translated using the Molecular Evolutionary Genetic Analysis software package (MEGA 7) (Kumar et al. 2016). Nucleotide and amino acid sequences from each isolate were then aligned using BioEdit Sequence Alignment Editor 7.1.9 to detect polymorphisms among $R$. microplus ATAQ sequences. Amino acid sequences from each isolate were grouped according to identity/similarity using the SIAS tool (http://imed.med.ucm. es/Tools/sias.html).

\section{Phylogenetic analysis}

Phylogenetic analysis was based on comparison of the ATAQ sequences obtained and reference sequences of $A T A Q$ and Bm86 genes deposited in the GenBank database. Evolutionary history was inferred using the maximum 


\begin{tabular}{|c|c|c|c|c|c|c|c|c|c|c|c|c|c|}
\hline & 25 & 35 & 86 & 90 & 177 & 195 & 330 & 352 & 387 & 396 & 424 & 447 & 463 \\
\hline R. microplus Media Joya & $\mathrm{C}$ & $\mathrm{C}$ & G & A & A & G & G & G & G & A & G & C & c \\
\hline R. microplus vargas & $\mathrm{T}$ & . & A & G & - & - & - & - & - & - & - & - & - \\
\hline R. microplus Verdineno & $\mathrm{T}$ & . & A & G & . & . & - & - & . & . & . & - & - \\
\hline R. microplus Hybrid & $\mathrm{T}$ & . & A & G & . & . & . & - & . & . & . & . & . \\
\hline R. microplus Campeche & $\mathrm{T}$ & . & A & G & . & . & - & C & $\mathrm{T}$ & C & $\cdot$ & $\mathrm{T}$ & G \\
\hline R. microplus Huastecas & $\mathrm{T}$ & $\mathrm{T}$ & A & . & G & A & . & $\mathrm{C}$ & $\mathrm{T}$ & $\mathrm{C}$ & A & $\mathrm{T}$ & G \\
\hline R. microplus Moyahua & $\mathrm{T}$ & . & A & . & G & . & A & $\mathrm{C}$ & $\mathrm{T}$ & $\mathrm{C}$ & . & $\mathrm{T}$ & G \\
\hline \multirow[t]{2}{*}{ R. microplus } & $\mathrm{T}$ & . & A & G & . & . & . & . & . & . & . & . & . \\
\hline & 487 & 531 & 567 & 577 & 706 & 771 & 793 & 795 & 834 & 837 & 881 & 882 & 986 \\
\hline R. microplus Media Joya & G & G & A & A & $\mathrm{T}$ & A & G & A & A & $\mathrm{C}$ & A & $\mathrm{C}$ & G \\
\hline R. microplus vargas & - & . & - & - & - & . & - & - & - & - & - & - & $\mathrm{T}$ \\
\hline R. microplus Verdineno & . & A & . & . & - & - & . & - & - & - & - & - & - \\
\hline R. microplus Hybrid & - & - & - & - & . & - & - & - & - & - & - & - & . \\
\hline R. microplus Campeche & A & . & $\mathrm{C}$ & C & . & . & . & . & . & . & G & . & . \\
\hline R. microplus Huastecas & A & A & C & C & C & G & A & G & $\mathrm{C}$ & G & G & $\mathrm{T}$ & - \\
\hline R. microplus Moyahua & A & A & $\mathrm{C}$ & C & . & . & . & - & . & - & G & . & - \\
\hline \multirow[t]{2}{*}{ R. microplus Mozambique } & - & - & - & - & $\cdot$ & $\cdot$ & - & - & - & $\cdot$ & $\cdot$ & - & $\cdot$ \\
\hline & 1001 & 1137 & 1152 & 1161 & 1170 & 1410 & 1413 & 1421 & 1464 & 1611 & 1695 & 1701 & \\
\hline R. microplus Media Joya & A & A & A & A & $\mathrm{T}$ & $\mathrm{T}$ & C & G & C & C & A & G & \\
\hline R. microplus vargas & - & - & - & - & - & - & - & - & - & $\cdot$ & C & A & \\
\hline R. microplus verdineno & - & G & G & - & - & - & - & - & - & A & C & A & \\
\hline R. microplus Hybrid & - & - & . & - & - & - & - & - & - & A & C & A & \\
\hline R. microplus Campeche & . & G & G & $\mathrm{T}$ & $\mathrm{C}$ & - & - & - & $\cdot$ & A & C & A & \\
\hline R. microplus Huastecas & G & G & G & $\mathrm{T}$ & C & G & $\mathrm{T}$ & A & G & - & - & - & \\
\hline R. microplus Moyahua & G & G & G & $\mathrm{T}$ & C & . & $\mathrm{T}$ & - & . & A & C & . & \\
\hline R. microplus Mozambique & . & . & . & . & . & . & . & . & . & A & $\mathrm{C}$ & A & \\
\hline
\end{tabular}

Fig. 1 Alignment of R. microplus ATAQ nucleotide sequences. DNA sequences are shown in the single letter nucleotide code. Identical nucleotides are shown with dots. Numbers correspond to the R. microplus "Media Joya" ATAQ sequence

likelihood method (ML) (Guindon and Gascuel 2003) based on the Kimura 2-parameter substitution model (Kimura 1980). A gamma distribution was used to model evolutionary rate differences among sites with 2 categories and with invariable sites. To test the robustness of branches in phylogenetic trees, 1000 cycles of bootstraps were used (Felsenstein 1985). All evolutionary analyses were conducted in MEGA 7 software.

\section{Results and discussion}

In the present study, the complete coding region of the R. microplus ATAQ gene was amplified from tick isolates of 7 different geographical locations in Mexico. Nucleotide sequence data reported in this paper were submitted to GenBank
(NCBI) with the accession numbers: MF314445.1 (Media Joya), MF314446.1 (Moyahua), MF314447.1 (Huastecas), MG437296.1 (Campeche), MG437297.1 (Hybrid), MG437298.1 (Verdineño), and MG437299.1 (Vargas). Comparison of the ATAQ nucleotide sequences from the Mexican isolates with the "Mozambique" ATAQ sequence showed polymorphisms in 38 positions (Fig. 1), which affected the conservation of a total of 20 residues as shown in the amino acid sequence alignment (Fig. 2). The ATAQ sequences also showed regions of extensive similarity between amino acids 29-110, 193-236, 474-537, and 567-606 among R. microplus isolates.

Genetic analysis provides evidence of gene function and genetic variation in ticks, the latter being suggested as a factor in the variable efficacy between tick species and geographical 


\begin{tabular}{|c|c|c|c|c|c|c|c|c|c|c|}
\hline & 9 & 12 & 29 & 110 & 118 & 142 & 155 & 163 & 193 & 236 \\
\hline R. microplus Media Joya & $\mathrm{P}$ & A & G & M & $\mathrm{E}$ & $\mathrm{V}$ & $\mathrm{L}$ & $\mathrm{D}$ & $\mathrm{N}$ & $\mathrm{Y}$ \\
\hline R. microplus Vargas & $\mathrm{S}$ & - & $\mathrm{E}$ & - & - & - & - & - & - & - \\
\hline R. microplus Verdineno & S & - & $\mathrm{E}$ & - & - & - & - & - & - & - \\
\hline R. microplus Hybrid & $\mathrm{S}$ & - & $\mathrm{E}$ & - & - & - & - & - & - & - \\
\hline R. microplus Campeche & $\mathrm{S}$ & - & $\mathrm{E}$ & - & $Q$ & - & $\mathrm{V}$ & $\mathrm{N}$ & $\mathrm{H}$ & - \\
\hline R. microplus Huastecas & $\mathrm{S}$ & $\mathrm{V}$ & $\mathrm{E}$ & - & $Q$ & I & V & $\mathrm{N}$ & $\mathrm{H}$ & $\mathrm{H}$ \\
\hline R. microplus Moyahua & S & . & E & I & $Q$ & - & $\mathrm{V}$ & $\mathrm{N}$ & $\mathrm{H}$ & . \\
\hline R. microplus Mozambique & $\mathrm{S}$ & - & E & - & - & - & - & - & - & - \\
\hline & 265 & 278 & 279 & 294 & 329 & 334 & 470 & 474 & 537 & 567 \\
\hline R. microplus Media Joya & $\mathrm{E}$ & K & D & $\mathrm{D}$ & W & $Q$ & $\mathrm{~N}$ & $\mathrm{R}$ & $\mathrm{H}$ & M \\
\hline R. microplus Vargas & - & - & - & - & $\mathrm{L}$ & . & - & - & - & I \\
\hline R. microplus Verdineno & - & - & - & - & - & - & - & - & $Q$ & I \\
\hline R. microplus Hybrid & . & . & - & . & . & . & - & - & $Q$ & I \\
\hline R. microplus Campeche & - & . & . & G & - & . & - & - & $Q$ & I \\
\hline R. microplus Huastecas & K & $\mathrm{N}$ & $\mathrm{E}$ & G & - & $\mathrm{R}$ & K & $Q$ & - & - \\
\hline R. microplus Moyahua & . & . & . & G & - & $\mathrm{R}$ & . & . & $Q$ & . \\
\hline R. microplus Mozambique & . & . & . & . & . & . & . & . & $Q$ & I \\
\hline
\end{tabular}

Fig. 2 Alignment of $R$. microplus ATAQ protein sequences. Protein sequences are shown in the single letter amino acid code. Identical amino acids are shown with dots. Numbers correspond to the R. microplus "Media Joya" ATAQ sequence

Fig. 3 Phylogenetic relationship of ATAQ sequences. The number represents the percentage of 1000 replications (bootstrap support) at each node of branches. The country of origin and GenBank accession number are indicated. Sequences data generated in the present study are highlighted in bold

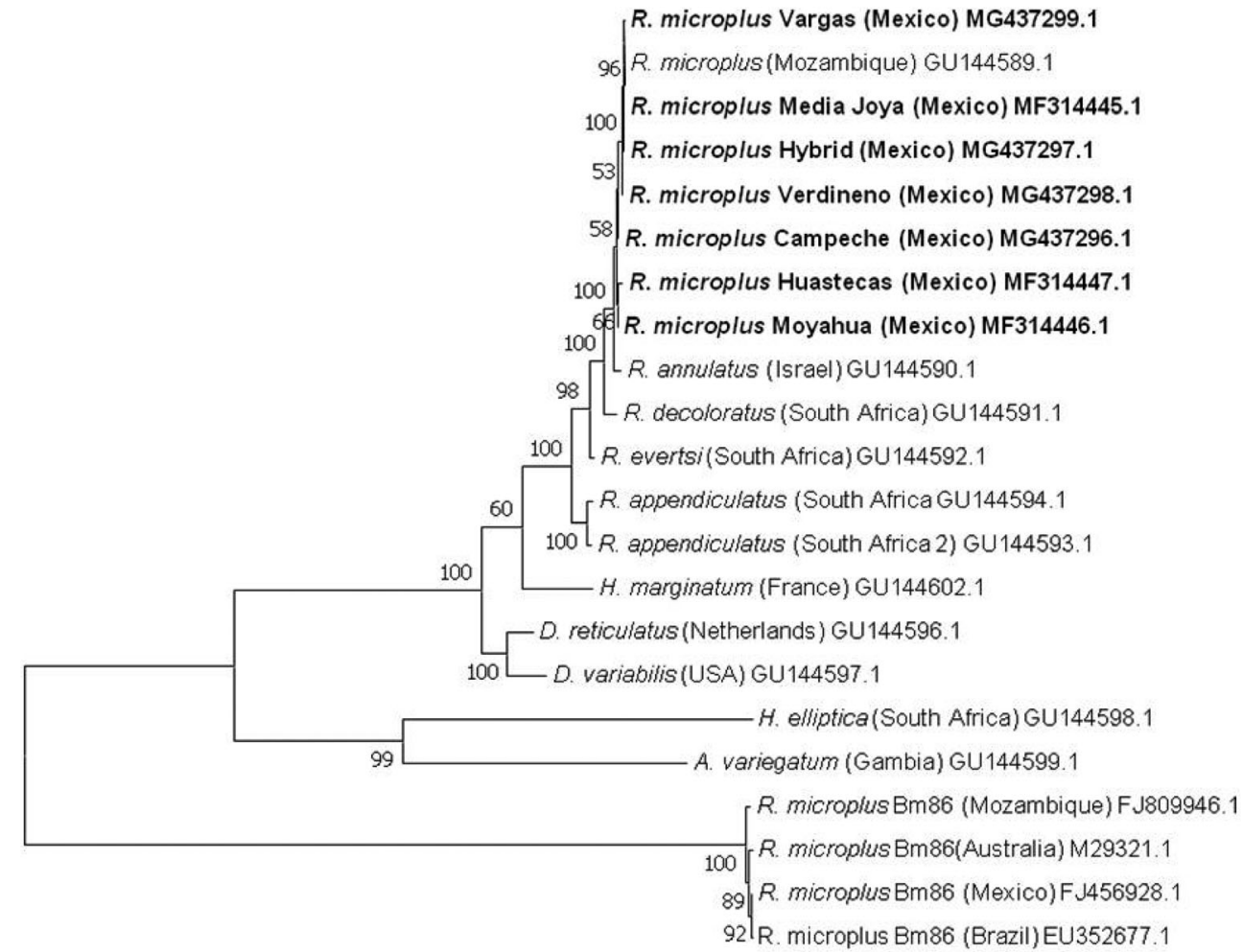




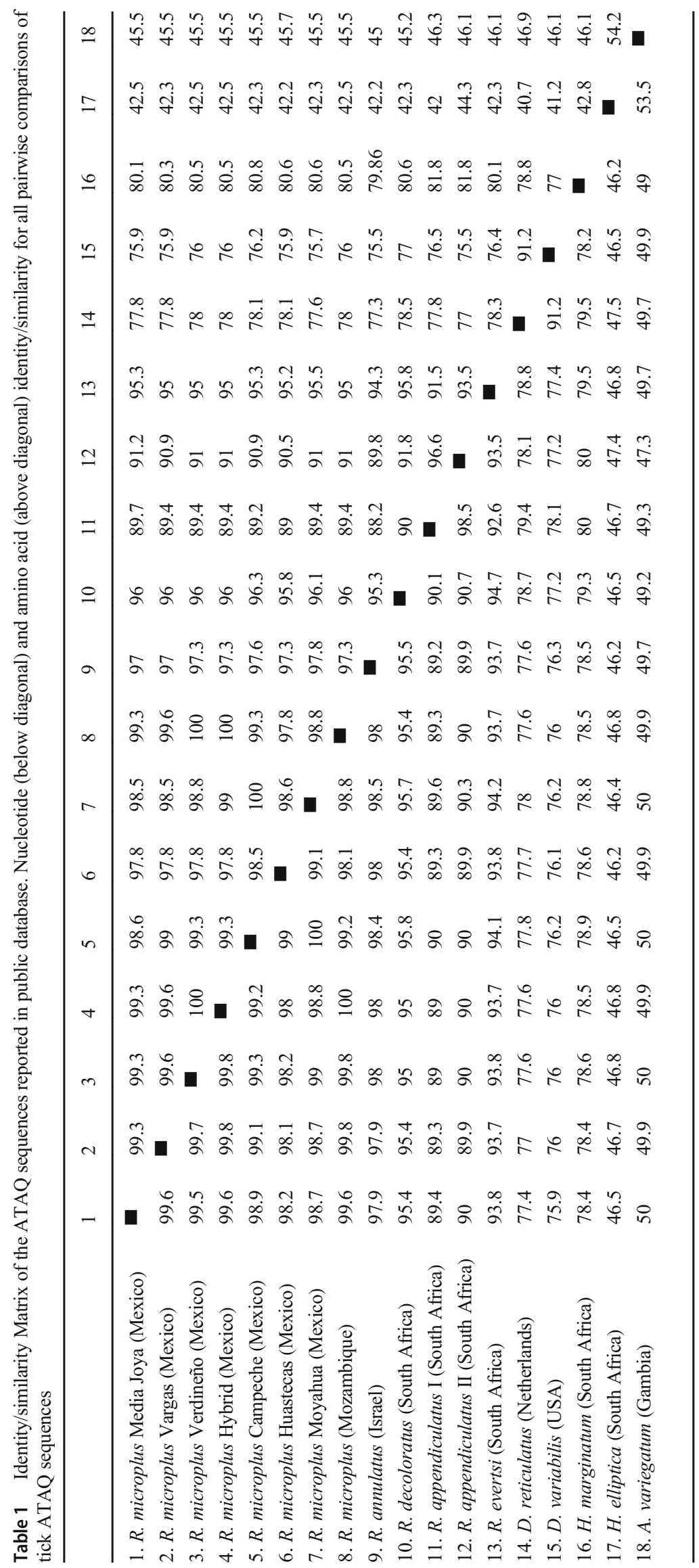


strains in cattle vaccination trials, since ticks from several regions have experienced through different evolutionary processes (García-García et al. 1999). The results were focused on the relationship between $R$. microplus and other tick species. Phylogenetic reconstruction showed that all the Mexican isolates, together with the $R$. microplus "Mozambique" ATAQ, were grouped into one clade; thus, sequences obtained indicate genetic proximity with the "Mozambique" ATAQ sequence (Fig. 3). Moreover, our analysis provides strong evidence of conservation of the ATAQ gene among the Rhipicephalus genus (100\% bootstrap support), similar to results reported in previous studies (Nijhof et al. 2010). The genetic analysis of the ATAQ gene indicated that the sequences obtained from the "Media Joya," "Vargas," "Verdineño," and "Hybrid" isolates showed a high degree of identity/similarity ( 99.8\%) to the "Mozambique" ATAQ sequence. Conversely, "Campeche," "Huastecas," and "Moyahua" isolates showed 98.1-99.2\% identity and 97.899.3\% similarity to the "Mozambique" ATAQ (Table 1). The ML tree inferred from the $A T A Q$ gene is consistent with the amino acid tree, displaying identical topology (data not shown). However, sequence identity between $R$. microplus with Haemaphysalis elliptica (46.5\%) and Amblyomma variegatum (50\%) was lower than with other species such as Hyalomma marginatum (78.4\%) and Dermacentor spp. ( $76 \%$ ). The phylogeny of ticks obtained with ATAQ and Bm86 sequences was similar to the findings by Nijhof et al. (2010). Additionally, our results agree with previous reports on the evolution of the Bm86 protein family and suggest that the ATAQ proteins have evolved in two gene duplication events through its formation (prostriate and metastriate lineages). The ATAQ protein is an attractive candidate for the development of an anti-tick vaccine due to its anatomical location compared with Bm86. Furthermore, the expression in two vital organs (midgut and Malpighian tubules) of all ticks and its structural similarity to Bm86 suggest that vaccination with ATAQ protein would confer strong protection against multiple tick species.

Recently, Aguirre et al. (2016) designed a synthetic peptide from the $R$. microplus ATAQ protein (GenBank: ADR01301.1), located between residues 531 and 547 (NH2PQPPHHQKWPFPTTPMA-COOH) with several antigenic properties. The researchers evaluated this peptide against Rhipicephalus sanguineus and $R$. microplus with an average protection efficacy of $31 \%$. Interestingly, our results detected a polymorphism within that linear B cell peptide in three Mexican R. microplus ATAQ sequences located in the position 537. The peptide contains glutamine (Q) instead of a histidine $(\mathrm{H})$ in "Media Joya," "Vargas," and "Huastecas" isolates. This result might indicate the possible reason why the synthetic peptide elicited a weak protective antibody response in host species and a poor reduction in all parameters evaluated when it was tested in both Rhipicephalus ticks. This is consistent with previous experimental trials of tick vaccines (García-García et al. 1999, 2000; Willadsen 2004; Anbrasi et al. 2014). The results clearly suggest that sequence divergence has a direct effect on the antigenicity of vaccines, and it is not enough to use bioinformatics strategies to design a multi-target vaccine directed to the control of tick infestations, without first analyzing the genetic variability of the target and physiological factors that could decrease the efficacy of tick vaccines (Freeman et al. 2010; Popara et al. 2013; Anbarasi et al. 2014). As discussed previously, it is essential to identify and analyze proteins in full detail, and above all, use the genetic material from predominating tick strain in a specific geographical location for the development of anti-tick vaccines (Canales et al. 2009; Moreno-Cid et al. 2013; Shakya et al. 2014).

\section{Conclusion}

This is the first report that estimates variation of $R$. microplus $A T A Q$ gene in Mexico, which was demonstrated through genetic analysis among geographic isolates of the same species. Analyses of $A T A Q$ gene sequences showed a high degree of conservation among them, suggesting a conservation of antigenic determinants in the ATAQ protein; however, specific polymorphisms were identified, which may be responsible for the variations of antigenic features, and must be taken into account when designing an ATAQ protein-based vaccine. Further research is necessary, exploring genetic and physiological diversity among national tick isolates from other geographical regions and among different tick species. Finally, vaccination experiments with the full recombinant ATAQ protein are essential to suggest this antigen as a vaccine candidate that might control tick infestations.

Acknowledgments We thank Gabriela Granjeno (CENID-SAI, INIFAP) for technical assistance.

Funding information This study was supported by Instituto Nacional de Investigaciones Forestales, Agrícolas y Pecuarias (INIFAP), project 11232433025 entitled "Caracterización, aislamiento y clonación del gen que codifica el Canal de cloro activado por glutamato ( $\mathrm{GluCl}$ ) de garrapatas Rhipicephalus (Boophilus) microplus resistente a ivermectina y su uso potencial para diagnóstico."

\section{Compliance with ethical standards}

Conflict of interest The authors declare that they have no conflict of interest.

\section{References}

Aguirre AA, Lobo FP, Cunha RC, Garcia MV, Andreotti R (2016) Design of the ATAQ peptide and its evaluation as an immunogen to develop a Rhipicephalus vaccine. Vet Parasitol 221:30-38 
Almazán C, Lagunes R, Villar M, Canales M, Rosario-Cruz R, Jongejan F, de la Fuente J (2010) Identification and characterization of Rhipicephalus (Boophilus) microplus candidate protective antigens for the control of cattle tick infestations. Parasitol Res 106:471-479

Anbarasi P, Latha BR, Dhinakar R, Sreekumar C, Senthuran S (2014) Partial sequencing of $B m 86$ gene for studying the phylogeny of an Indian isolate of Rhipicephalus (Boophilus) microplus tick. J Parasit Dis Journal of Parasitic Diseases 38:260-264

Blecha IMZ, Csordas BG, Aguirre AAR, Cunha RC, Garcia MV, Andreotti R (2018) Analysis of Bm86 conserved epitopes: is a global vaccine against cattle tick Rhipicephalus microplus possible? Rev Bras Parasitol Vet 2:267-279

Canales M, Almazán C, Naranjo V, Jongejan F, de la Fuente J (2009) Vaccination with recombinant Boophilus annulatus Bm86 ortholog protein, $\mathrm{Ba} 86$, protects cattle against $B$. annulatus and $B$. microplus infestations. BMC Biotechnol 9:29-35

Felsenstein J (1985) Confidence limits on phylogenies: an approach using the bootstrap. Evolution 39:783-791

Freeman JM, Davey RB, Kappmeyer LS, Kammlah DM, Olafson PU (2010) Bm86 midgut protein sequence variation in South Texas cattle fever ticks. Parasit Vectors 3:101

García-García JEC, González IL, González DM, Valdés M, Méndez L, Lamberti J, B'Agostino B, Citroni D, Fragoso H, Ortiz M, Rodríguez M, de la Fuente J (1999) Sequence variations in the Boophilus microplus Bm86 locus and implications for immunoprotection in cattle vaccinated with this antigen. Exp Appl Acarol 23:883-895

García-García JC, Montero C, Redondo M, Vargas M, Canales M, Boue O, Rodríguez M, Joglar M, Machado H, González IL, Valdés M, Méndez L, de la Fuente J (2000) Control of ticks resistant to immunization with $\mathrm{Bm} 86$ in cattle vaccinated with the recombinant antigen Bm95 isolated from the cattle tick, Boophilus microplus. Vaccine 18:2275-2287

Guerrero FD, Miller RJ, Pérez de León AA (2012) Cattle tick vaccines: many candidate antigens, but will a commercially viable product emerge? Int J Parasitol 42:421-427

Guindon S, Gascuel O (2003) A simple, fast, and accurate algorithm to estimate large phylogenies by maximum likelihood. Syst Biol 52: 696-704

Kaewmongkol S, Kaewmongkol G, Inthong N, Lakkitjaroen N, Sirinarumitr T, Berry CM, Jonsson NN, Stich RW, Jittapalapong S (2015) Variation among Bm86 sequences in Rhipicephalus (Boophilus) microplus ticks collected from cattle across Thailand. Exp Appl Acarol 66:247-256

Kimura M (1980) A simple method for estimating evolutionary rates of base substitutions through comparative studies of nucleotide sequences. J Mol Evol 16:111-120

Kumar S, Stecher G, Tamura K (2016) MEGA 7 molecular evolutionary genetics version 7.0 for bigger datasets. Mol Biol Evol 33:18701874
Lagunes R, Domínguez-García D, Quiroz H, Martínez-Velázquez M, Rosario-Cruz R (2016) Potential effects on Rhipicephalus microplus tick larvae fed on calves immunized with a Subolesin peptide predicted by epitope analysis. Trop Biomed 33:726-738

Moreno-Cid JA, Pérez de la Lastra JM, Villar M, Jiménez M, Pinal R, Estrada-Peña A, Molina R, Lucientes J, Gortázar C, de la Fuente J (2013) Control of multiple arthropod vector infestations with subolesin/akirin vaccines. Vaccine 31:1187-1196

Nijhof AM, Balk JA, Postigo M, Rhebergen AM, Taoufik A, Jongejan F (2010) Bm86 homologues and novel ATAQ proteins with multiple epidermal growth factor (EGF)-like domains from hard and soft ticks. Int J Parasitol 40:1587-1597

Parizi LF, Githaka NW, Logullo C, Konnai S, Masuda A, Ohashi K, da Silva Vaz I Jr (2012). The quest for a universal vaccine against ticks: cross-immunity insights. Vet J 194: 158-165

Popara M, Villar M, Mateos-Hernández L, Fernández de Mera IG, Marina A, del Valle M, Almazán C, Domingos A, de la Fuente J (2013) Lesser protein degradation machinery correlates with higher BM86 tick vaccine efficacy in Rhipicephalus annulatus when compared to Rhipicephalus microplus. Vaccine 31:4728-4735

Ramírez PB, Rosario Cruz R, Domínguez DI, Hernández R, Lagunes R, Ortuño D, González C, Gutiérrez A, Herrera SE, Vallejo A, Martínez M (2016) Identification of immunogenic proteins from ovarian tissue and recognized in larval extracts of Rhipicephalus (Boophilus) microplus, through an immunoproteomic approach. Exp Parasitol 170:227-235

Rodríguez-Mallon A (2016) Developing anti-tick vaccines. Methods Mol Biol 1404:243-259

Rodríguez-Vivas R, Grisi L, Pérez de León A, Silva H, Torres-Acosta J, Fragoso H, Romero D, Rosario R, Saldierna F (2017) Potential economic impact assessment for cattle parasites in Mexico. Rev Mex Cienc Pecu 8:61-74

Schetters T, Bishop R, Crampton M, Kopáček P, Lew-Tabor A, MaritzOlivier C, Miller R, Mosqueda J, Patarroyo J, Rodriguez-Valle M, Scoles GA, de la Fuente J (2016) Cattle tick vaccine researchers join forces in CATVAC. Parasit Vectors 9:105

Shakya M, Kumar B, Nagar G, de la Fuente J, Ghosh S (2014) Subolesin: a candidate vaccine antigen for the control of cattle tick infestations in Indian situation. Vaccine 32:3488-3494

Sossai S, Peconick AP, Sales-Junior PA, Marcelino FC, Vargas MI, Neves ES, Patarroyo JH (2005) Polymorphism of the Bm86 gene in South American strains of the cattle tick Boophilus microplus. Exp Appl Acarol 37:199-214

Willadsen P (2004) Anti-tick vaccines. Parasitology 129:S1-S21

Publisher's note Springer Nature remains neutral with regard to jurisdictional claims in published maps and institutional affiliations. 